\title{
Natural disasters and their aftermath
}

\author{
David Skuse
}

Behavioural and Brain Sciences Unit, Institute of Child Health, London WC1 1EH, UK, email d.skuse@ich.ucl.ac.uk

Less attention

is now paid to isolated incidents

that came in

an instant but

then passed by,

leaving in their

wake terrible

destruction. Initial

concern has not

exactly turned into

indifference, but

in the aftermath

of acute events it

is hard to sustain

great interest for

months on end.

\section{Entire societies \\ find ways of \\ adjusting, of \\ supporting one \\ another, of coming \\ to terms with what \\ has happened, \\ and they do not \\ always need \\ focused psychiatric \\ intervention to \\ work through their \\ grief.}

\section{The} he chronic trauma endured by the people of Iraq, Darfur and Zimbabwe is a subject regularly brought to our attention in the UK by the news media. The mental health risk attributable to living in a situation in which each day brings the threat of more disruption, another risk to life and limb, the loss of people you love, perhaps of your home, is great. Less attention is now paid to isolated incidents that came in an instant but then passed by, leaving in their wake terrible destruction. Initial concern has not exactly turned into indifference, but in the aftermath of acute events it is hard to sustain great interest for months on end. Yet, for those who inhabit the rim of land in the Indian Ocean affected by the tsunami of December 2004, one single event did bring about unimaginable destruction and loss of life. In Kashmir in October 2005, an earthquake destroyed communities within a huge geographical area, one that was far more isolated, and hence less accessible to reporters, than the beaches of Phuket. From time to time we may wonder what happened to the survivors of these disasters - how are they coping, what help has been made available to them since, and to what extent have political complexities in Indonesia, Sri Lanka and Kashmir influenced the availability of aid and assistance?

To an extent, we gain some answers to these questions from this issue's thematic papers. Professors Chadda and Malhotra travelled to the earthquakeaffected region of Kashmir to support local teams who were attempting to provide mental health services to the surviving population. The immediate need was to provide appropriate training to doctors and associated professionals who were already there, and who were going to be in a position to give continuing support to the population traumatised by the quake. Was there an immediate need for psychiatric intervention? The visiting psychiatrists were met with initial scepticism, yet they did manage to give advice on follow-up treatment to a great many medical and paramedical teams during brief training programmes.

In northern Sri Lanka the threat of terrorism has complicated the response of teams assisting the local population in the wake of the tsunami that killed over
40000 people in that country. The review of psychosocial adjustment 10 months later by Danvers et al is an important contribution to our understanding of population responses to such a tragedy. The scale of loss was so great and so many families were affected that a community response was inevitable. Sensibly, the psychiatric intervention teams focused on that minority who had serious mental health needs before the disaster, or who had unusually severe or prolonged responses afterwards. Previous traumas affecting those who lived in territories disputed by the Tamil Tigers had apparently steeled them to cope, and they did so rather better than might have been expected. Sadly, despite unprecedented quantities of aid being available, this is still not reaching all those who need it.

Professor Diyanath Samarasinghe has summarised key issues concerning the response to the tsunamirelated havoc in Sri Lanka, and in a valuable contribution sets out specific needs that are associated with acute disasters. He emphasises, as do our other contributors, that disasters affecting whole communities differ in their impact, and their implications for mental health, from traumatic events that affect individuals (such as terrorist bombings). Entire societies find ways of adjusting, of supporting one another, of coming to terms with what has happened, and they do not always need focused psychiatric intervention to work through their grief. There is a danger inherent in the power imbalance between those who are victims and the authorities set up to assist them, but the instigation of some formal system of societal control is urgent and necessary.

Finally, in a Point of View piece, Professor Murad Khan finds confusion and lack of leadership among the authorities in Pakistan in the provision of psychiatric assistance to those affected by the October 2005 earthquake. In a hard-hitting review of the psychosocial relief programmes provided, he makes a plea for a greater role to be played in future by the Pakistan Psychiatric Society. This institution could, and should, be responsible for the coordination and provision of mental health programmes - and there is no time like the present to press for reform.

Politicians (and psychiatrists) on the couch

A colleague writes of the widespread concern in some African countries about the behaviour of politicians in office. But this is not a matter of concern only for Africans. The press has been speculating whether aspirants to high political office should undergo psychiatric or psychological testing before being deemed eligible for election. This may not be a novel idea, as in many industries it is common to conduct such screening before selection for key posts. It has always interested this member of the editorial board that psychiatrists do not have to go through such assessments. These are surely all serious matters and psychologists and psychiatrists should contribute to the debate. — Brian Martindale 